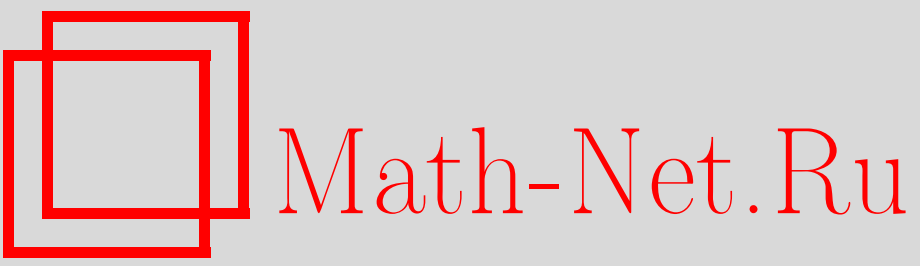

А. О. Иванов, А. А. Тужилин, Классификация минимальных скелетов с правильной границей, УМН, 1996, том 51, выпуск 4, 157-158

DOI: https://doi.org/10.4213/rm1002

Использование Общероссийского математического портала Math-Net.Ru подразумевает, что вы прочитали и согласны с пользовательским соглашением

http://www.mathnet.ru/rus/agreement

Параметры загрузки:

IP : 54.147 .182 .235

26 апреля 2023 г., 15:36:27 


\title{
КЛАССИФИКАЦИЯ МИНИМАЛЬНЫХ СКЕЛЕТОВ С ПРАВИЛЬНОЙ ГРАНИЦЕЙ
}

\author{
А.О. Иванов, А.А. Тужилин
}

Задача описания всех плоских локально минимальных сетей, затягивающих вершины правильных многоугольников (в дальнейшем - сетей с правильной границей), была поставлена академиком А. Т. Фоменко [1]. В качестве первого шага на пути решения этой задачи, авторы начали изучение локально минимальных бинарных деревьев с правильной границей [2]-[6]. В настоящей работе получено полное описание всех возможных топологий важного класса таких деревьев минимальных скелетов с правильной границей (см. ниже).

Хорошо известно, что минимальные бинарные деревья могут быть полностью описаны как плоские бинарные деревья, все ребра которых - прямолинейные отрезки, стыкующиеся между собой в вершинах степени 3 под углами, равными $120^{\circ}$. Множество $M$ всех вершин степени 1 из $\Gamma$ называется границей $\Gamma$. Если $M$ лежит на границе своей выпуклой оболочки, то говорят, что Г имеет выпуклую гранииу.

Существует естественное взаимно однозначное соответствие (с точностью до планарной эквивалентности) между плоскими бинарными деревьями и триангуляциями диагоналями плоских многоугольников (двойственный граф̆ каждой такой триангуляции является бинарным деревом).

Пусть $T$ - некоторая диагональная триангуляция многоугольника $P$. Cmепенью вериины $V$ триангуляции $T$ называется количество треугольников из $T$, для которых $V$ является вершиной. Сторона многоугольника $P$ называется концевой, если степени ее вершин равны 1 и 2 . Треугольник из $T$ назовем крайним, если не меньше двух его сторон лежит на границе многоугольника $P$. Если все стороны треугольника из $T$ лежат внутри $P$, то он называется внутренним. Крайний треугольник называется наростом, если он примыкает к некоторому внутреннему треугольнику. Триангуляция $T$, не имеющая наростов, называется скелетом. Плоское 2-дерево $\Gamma$ назовем скелетом, если соответствующая триангуляция $T$ является скелетом.

Пусть $T$ - некоторый скелет. Выбросим из скелета $T$ все внутренние треугольники. Связные компоненты полученной триангуляции назьваются линейнымм участками скелета $T$. Линейный участок скелета $T$ называется концом скелета $T$, если он содержит крайний треугольник из $T$. Скелет, совпадающий со своим единственным концом, называется линейным. Линейный скелет называется змеей, если степень каждой его вершины не превосходит 3 . Конец нелинейного скелета называется змеей, если он является змеей как скелет и пересекается с внутренним треугольником из $T$ по одному из своих концевых ребер.

Из результатов [2]-[6] вытекает, что если минимальный скелет Г затягивает вершины выпуклого многоугольника, то число концов скелета $\Gamma$ не превосходит 6 . В настоящей работе получена полная классификация всех минимальных скелетов с правильной границей с точностью до планарной эквивалентности.

ТеОРема. Пусть $M$ - множсество вериин правильного многоугольника $и$ $n \geqslant 3$ количество его вериин.

- Если остаток от деления п на 6 равен трем и $n \geqslant 9$, то существуют два затягивающих $M$ минимальных скелета, один из которых является змеей, а другой имеет три планарно әквивалентных между собой конца-змеи, причем степени вериин единственного внутренненго треугольника этого скелета равнь между собой.

- Если п равно 24, 30, 36 или 42, то существуют два затягивающих М минимальных скелета, один из которых является змеей, а триангуляция второго изображена на рисунке.

Авторы пользуются частичной поддержкой грантов Международного научного фонда (ISF), Международной Ассоциации по содействию сотрудничеству с учеными независимых государств бывшего Советского Союза (INTAS) и Российского фонда фундаментальных исследований (РФФИ). 
- Во всех остальных случаях существует единственный минимальный скелет Г, затягивающий $M$, и этот скелет является змеей.
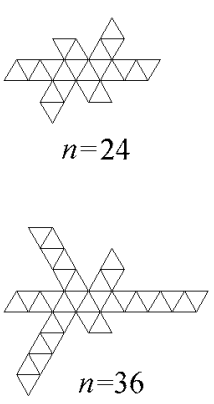
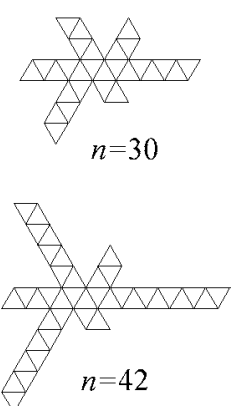

Теперь, для завершения описания всех минимальных бинарных деревьев с правильной границей, необходимо разобраться, как могут быть расположены наросты на соответствующих триангуляциях. См. примеры в [4], [5], [7].

Авторы пользуются случаем выразить искреннюю признательность академику А. Т. Фоменко за постоянное внимание к работе.

\section{СПИСОК ЛИТЕРАТУРЫ}

[1] Фоменко А. Т. Топологические вариационные задачи. М.: Изд-во МГУ, 1984. [2] Иванов А. О., Тужилин А. А. // УМН. 1990. Т. 45. № 2. С. 207-208. [3] Иванов А. О., Тужилин А.А. // Матем. сб. 1991. Т. 182. №12. С. 1813-1844. [4] Иванов А. О., Тужилин А. А. // УМН. 1992. Т. 47. №2. С. 53-115. [5] Ivanov A. O., Tuzhilin A. A. // Adv. Soviet Math. 1993. V. 15. Р. 93-131. [6] Иванов А. О., Тужилин А. А. // УМН. 1995. Т. 50. №3. C. 155-156. [7] Ivanov A. O., Tuzhilin A. A. Minimal Networks. Steiner Problem and Its Generalizations. CRC Press, 1994.

Московский государственный университет им. М. В. Ломоносова
Принято редколлегией 18.04.1996 